\title{
The influence of micro and macro porosity of paper on wet repellence mottling in offset printing
}

\begin{abstract}
Fountain solution induced mottling in offset printing manifests as nonhomogenous printing area with optical variation has several influencing factors. One mechanism is that the fountain solution from the previous printing unit has no time to absorb into the coating before ink transfer or the ink cannot emulsify the water and stays on top of the ink surface as an additional hydrophilic layer. In paper coating development, the paper chemistry influences the surface chemistry features of the inkpaper coating interaction and can cause water repellency. Porosity and the absorbing capacity of paper and its coating is of great importance to avoid press related problems. In this paper, we have examined paper substrates which were reported to cause wet repellence mottling and tested their porosity ratio of micro and macro pores and their water/ ink absorption properties. The micro macro porosity was determined by using easy and low-cost proprietary technique for the porosity ratio determination. We have measured ink stabilization values, penetration dynamics, wet repellence mottling and micro and macro porosity on paper samples printed with laboratory sheet-fed offset printing. We have found that the lower number of macropores and non-optimal micro and macropore distribution influenced the occurrence of water induced wet repellence and lowered the optical homogeneity of the samples.
\end{abstract}

\author{
Igor Karlovits ${ }^{1}$ \\ Gregor Lavrič ${ }^{1}$ \\ Tomas Nemeš ${ }^{2}$ \\ ${ }^{1}$ Pulp and Paper Institute, \\ Ljubljana, Slovenia \\ ${ }^{2}$ University of Novi Sad, \\ Faculty of Technical Sciences, \\ Novi Sad, Serbia \\ Corresponding author: \\ Igor Karlovits \\ e-mail: \\ igor.karlovits@icp-lj.si
}

First recieved: 11.09.2018.

Accepted: 16.10.2018.

\section{KEY WORDS}

offset printing, mottling, wet repellence, paper porosity

\section{Introduction}

The paper substrate during printing in offset technology is exposed to two different liquids (printing inks and fountain solution). For good prints, the printing substrate has to separately absorb the fountain solution in a right time to allow printing in a subsequent printing unit, while the printing ink has to be held on the surface for better optical coverage. Besides that, the ink has to be firmly anchored by the partial separation of the printing ink vehicle to avoid smearing or scuffing. In general liquid penetration into porous materials is governed by two major properties: the geometry ("capillarity/porosity") and the energy ("contact angle"). Both in total yield sorptive behaviour. The geometry part is defined by the material components fibres, fillers, sizing agents and dyes for example. Also, there are air gaps (in fibres, between fibres and between different components in the paper structure or coating). The ratio of pore volume to a total volume of the sheet is called the porosity of the sheets which influences things like compressibility and the ability of paper to absorb fluids like ink, oils, and water (Bureau, 2000). In addition, in almost all converting operations, where liquids are forced into the sheet by the action of a nip, the porous structure of the base sheet is important. Thus, the characterization of the porous property, i.e., permeability, is of major importance for predicting the barrier and printing properties of paper products (Pal, Joyce \& Fleming, 2006). In printing, the absorption process of printing inks depends on absorptivity (the 
total volume of liquid) which can be taken in by the substrate. The pore size and diameter is not known so different pore size distribution can yield similar results. The diameter of the capillary structure of the paper determines the separation effects which drains off the ink vehicle part and leaves the pigment on or near the surface. If the diameter is too big the pigment particle can go through the porous network and induce internal light reflections which decrease the colour strength or other optical properties of the print. Also, the absorption rate determines the dynamic time dimension in the process of absorption and can be described by simple Hagen-Poiseuille flow law. Absorption rate rises with the increasing pore diameter while separation capacity decreases. With larger pores, absorption of the pigment and ink vehicle separation will be incomplete. So, the optimum pore diameter is defined primarily by the pigment particle which is used in the ink (Huber, 2013). As the flow of liquids and the interfacial interactions are complex subjects according to numerous researches Preston et al. (2002), Xiang et al. (2004), (Koivula, Bousfield \& Toivakka, 2010), (Schoelkopf, Gane \& Ridgeway, 2000) we shall concentrate on the ones most applicable to printing and paper like substrates. The ink setting phenomena in offset printing were covered extensively by Koivula (2012) in her PhD. Schoelkopf (2002) in his PhD thesis found that the absorption into porous network proceeds preferentially by the fine pores in that network. First by initial imbibitions together with the exclusion of larger pores by inertial retardation followed by viscosity controlled LW absorption dynamics. The remaining inertial retardation excludes the largest pores, and that this inertially driven selectivity leads to the establishment of a preferred pathway. Regarding differences in the competitive absorption of polar and non polar liquids into the latexbound porous structures Ridgway et al. (2011) found that in the porous structure without the latex coatings polar water instantly displaces the non polar liquids, while with latex binder which holds together the porous network the retardation of the polar water is observed. The required pre-wetting action of water vapour diffusion on the polyacrylate pigment surface is considered to be an integral part of the successful competition between oil and water in the offset printing process, as non-polar oil absorbs steadily into a water pre-saturated structure. Also, the structure of the printing inks (the type of the vehicle) determines the absorption through the pores.

Wet repellence mottling was also studied by Madstedt (2008) in her master thesis where some paper samples had a reduction in wet repellence mottling due to a decrease in the dampening solution. Also, the different amount of latex had no larger influence on this type of mottling but on back trap mottle. The coating weight influenced the speed of the absorption where a higher amount of the coating decreased the speed of the absorption. The distribution of the porosity is also important as a process parameter for calendaring or to improve the printing ink coating adhesion. Ridgeway and Gane (2005) made a research regarding smaller pores where they increased the number of ultrafine pores and increased simultaneously the pigment surface area to enable a capillary-driven separation of oils from solved resins and to provide higher adsorptive power for resins. The second way was that they introduced an oleophilic species into the coating structure, achieved by the inclusion of hydrophobic talc via a co-structure between talc and hydrophilic dispersed calcium carbonate. There were differences in the shortest times of absorption and their conclusion is that the observed improvements of ink adhesion are related to adsorptive mechanisms, and absorption rate governs the dwell time over which this adsorption can occur. Resch, Bauer \& Hirch (2010) researched the effect of calendaring on the pore structure change and its influence on the ink setting behaviour. Their findings indicate that fast ink setting can be realised by the use of fine pigments as well pigments with steep particle size distribution. On the other hand, their results demonstrate that the pore size of coated papers on average gets compressed permanently and reduced by using calendering. This trend towards smaller pores in their opinion should be beneficial but due to also denser coating structure which reduces the total numbers of voids (absorptivity) can lead to slower ink settings and problems in printing. From the review we can conclude the small pores benefit the mineral oil ink absorption through capillary effect and more small pores (micropores) induced good ink setting and drying, while larger (macro) pores are needed for the fountain solution absorption due to the high surface energy of the included water and filling in of micropores with printing ink. Essentially the ratio of the two can be a very valuable tool in paper production to reduce all printability problems.

\section{Methods and Materials}

In the experimental part, we concentrated on the absorption properties of the paper regarding the oil part of the inks and dampening solution (water) and the ratio between pores as it greatly influences the speed of the absorption of different liquids into the substrate. For all test we have tested both sides of the paper ( $A$ is the signature of the top side of the paper roll and $B$ the down/wire side of the paper roll when sampling) due to production variation regarding coating and calendaring differences in porosity can be induced. For example, higher calendaring close the macro pores which changes liquid/oil absorption behaviour. For the experimental part, we took 6 paper samples from the paper producer. The paper samples were from the same product line with different grammage and different production series. Some paper samples had the same grammage but were reported as not suitable for printing due to optical non-homogeneity. The basic paper properties of the samples are presented in Table 1. 


\section{Table 1}

Paper properties of the samples

\begin{tabular}{l|c|c|c}
\hline Property & $\begin{array}{c}\text { Samples } \\
\mathbf{1 , 2 , 3}\end{array}$ & $\begin{array}{c}\text { Samples } \\
\mathbf{4 , 5}\end{array}$ & $\begin{array}{c}\text { Sample } \\
\mathbf{6}\end{array}$ \\
\hline Grammage ISO 536:2012 [g/m²] & 60 & 54 & 57 \\
\hline $\begin{array}{l}\text { Specific volume ISO } \\
\text { 534:2011 [cm } / \mathrm{g}]\end{array}$ & $1.10-1.30$ & $1.10-1.30$ & $1.10-1.30$ \\
\hline $\begin{array}{l}\text { Tensile Strength ISO } \\
\text { 1924-2:2008 [N] }\end{array}$ & 42 & 40 & 39 \\
\hline $\begin{array}{l}\text { Opacity ISO 2471:2008 [\%] } \\
\text { Bendsten Roughness ISO } \\
8791-2: 2013[\mathrm{ml} / \mathrm{min}]\end{array}$ & 94 & 93 & 93 \\
\hline
\end{tabular}

* Samples with same grammage were from different production runs

Before testing all samples were conditioned according to the ISO 187:1990 standard. For the printing ink stabilization/set off test we checked the time dependent absorption properties of the oil/varnish component of the printing inks. We have used the Pruefbau printability tester with print speed of $0,5 \mathrm{~m} / \mathrm{s}$, print pressure and counter of $800 \mathrm{~N}$ and time delays for the measurement of 0,15 , 30, 60, 120 in 300 s. For printing we have used Huber Set Off inks (applied quantity of $1.5 \mathrm{~g} / \mathrm{m}^{2}$ ) and standard set off paper. After printing the values the optical density values were measured with $X$-Rite SpectroEye using the ISO 5-3:2009. The results are presented in Figure 1.

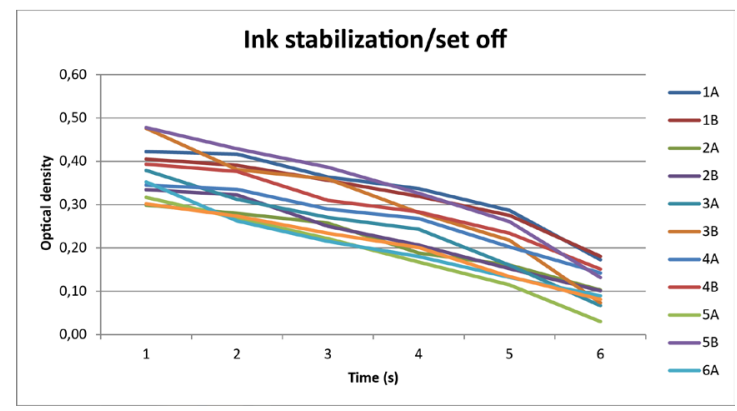

» Figure 1: Ink stabilization/set off results of different paper samples

As it can be observed From Figure 1 all paper had similar absorption trends of the oil component of the printing ink and have a linear trend of decline of the set off density values. The largest set off had the sample number 5 (B side ) and sample 1 ( $A$ and $B$ side). The smallest starting set off had the sample 5 (A side). As sample 5 had two most values (high and low) this indicates the sometimes the papers are "two-sided" regarding absorption and other properties due to inconsistencies in the production of it. The obtained values were in the typical range for offset commercial papers. After checking the oil/varnish part of the absorption we have checked the penetration dynamics of the water which simulated the dampening solution. The penetration dynamics was analyzed with Emtec PDA instrument which works on the measurement of the attenuation of the ultrasound. The paper sample is brought into contact with liquid and is radiated in the Z-direction with high-frequency low energy ultrasonic signals. These signals are received by a sensor and time-dependent values are calculated on the computer. For the analysis, we have used a mixture of distilled water (we have added $15 \%$ of IPA into the mixture) which simulated the dampening solution, and have measured them with $20 \mathrm{~mm}$ test area. This method is much more suitable for testing absorption properties regarding simpler but more often used Cobb water absorption test as it can give results in [ms/s] which is crucial for printing as the speed required a dampening solution to be absorbed between printing units in fraction of the second. The results of the absorption are presented in the form of a log/log time/signal scale in Figure 2.

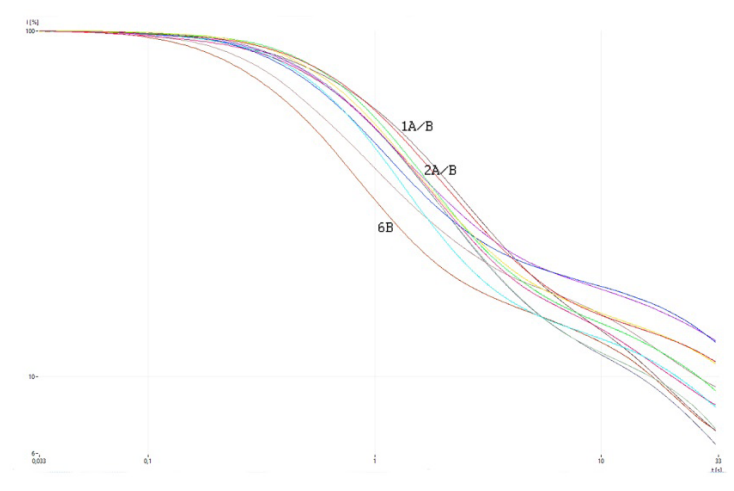

„ Figure 2: PDA curves of the samples

The larger the shoulder of the curve the denser »fine" microporous is the surface or the paper has a higher degree of sizing. Lower curves indicate quicker absorption and larger pores which absorb the the dampening solution mixture. In the time scale, it can be noted that the largest differences regarding penetration dynamics occur between 0,2 and $3 \mathrm{~s}$ which is the time range for offset printing (lower time values are more important for web offset printing). The smallest hydrophobicity had sample 6B while the quickest liquid absorption had sample 6B, while the slowest absorption had the samples 1 and 2 both sides ( $A$ and $B$ ).

To determine the micro and macro porosity ratio we have used the method developed by the Pulp and Paper Institute and which is described (Scheicher, 2009). The $\mathrm{micro} / \mathrm{macro}$ ratio is a dimensionless value defined by the measurement spot ( $\mathrm{nm}$ of light reflected) of the ink part which was absorbed and the ink part which was left on the surface. The method uses Porosimetric ink produced by IGT which is a special non-drying oil ink where the ink colour is defined by the dye which is soluble in the ink vehicle and has also pigment particles. Particle size distribution was determined using a Malvern Mastersizer 2000 particle size analyser. The fluid used 
as the dispersion medium (dispersant) was isopropyl alcohol. Hydro2000 Micro Precision, the dispersion unit for small amounts of material, was used for the measuring. The measurement of the sample was carried out in the dynamic mode. Measurement parameters were: pump speed $=2500$ rpm; ultrasonic=on. Applied Mie light scattering theory assumes that the particles are spheres so that the results obtained for particles size are equivalent sphere diameters. The particle size distribution of the ink is presented in Figure 3.

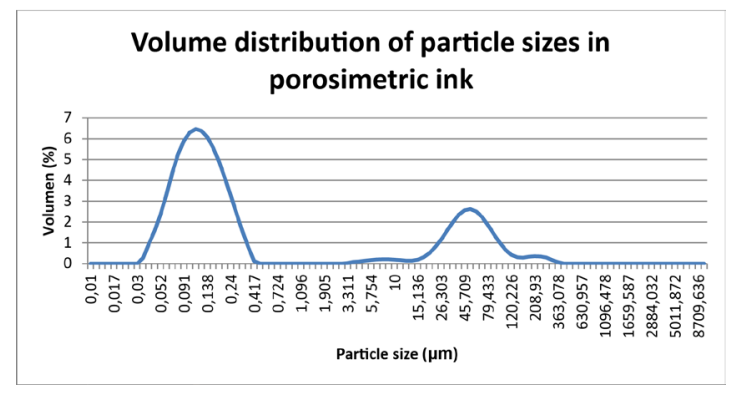

» Figure 3: Particle size distribution of the used porosimetric ink

As we can observe the porosimetric ink has two distinct peaks and particle distribution region and the pore system of paper acts as a filter for different particle sizes. Due to this property we can separate micro and macro pores (smaller or larger than $2 \mu \mathrm{m}$ ).

The prints were made using a GFL automated wipe off tester with amount of $1 \mu \mathrm{l}$ of ink which is applied for 2 minutes before wipe off. All the samples were measured with i1Pro2 spectrophotometer $45^{\circ} / 0^{\circ}$ ring illumination optics ISO 13655:2009 M0 measurement mode. We have measured the printed samples 5 times per patch and the values presented in Figure 4. are the averaged values of the measurements.

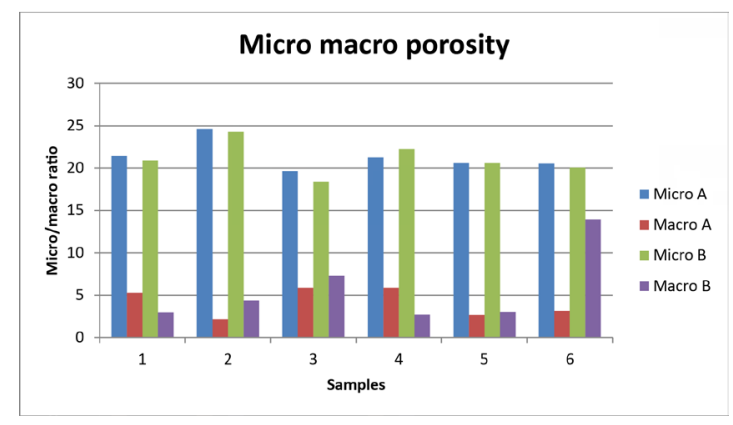

» Figure 4: Micro and macro porosity ratio values of the samples

All paper samples have similar values of micro pores (in relative number around 20), while there are larger scale differences in macro porosity. As we can see the largest number of macro pores has the $B$ side of sample 6 (above 10), while samples $1 A, 3 A, 3 B$ and $4 A$ have macro porosity values around 5 .
All other samples have lower value than 5 . The variation between A and B side was prominent in sample 6 .

To test the water repellence we used a modified test of the W59 Water interference mottle test by IGT adjusted to Pruefbau system. We have used $1 \mathrm{~m} / \mathrm{s}$ printing speed, pressure and counter pressure of $500 \mathrm{~N}$, and we have used a ready mixed dampening solution which contained IPA. For the printing inks we have used the printing inks provided by the paper producer (Sun Chemical SunLit). We have applied the dampening solution to a rubber roller in quantity of $30 \mathrm{~mL}$ and printing inks in the quantity of $1.2 \mathrm{~g} / \mathrm{m}^{2}$. After printing the print density of the samples was evaluated with measurement throughout the sample in 10 positions according to ISO 5-3:2009. The results can be viewed in Figure 5.

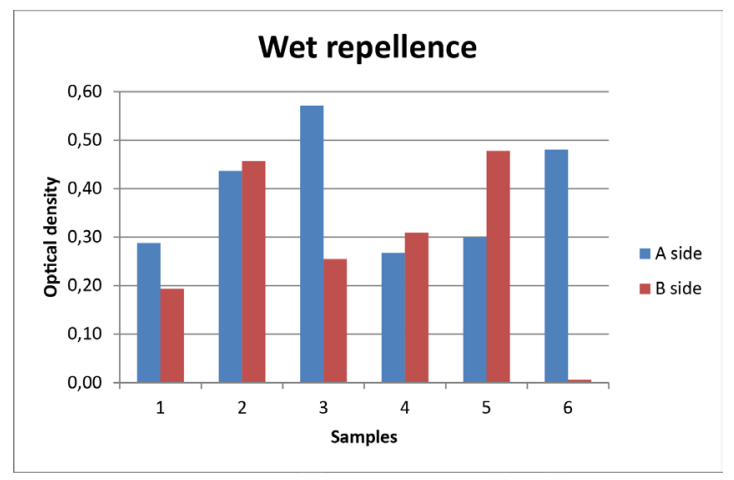

» Figure 5: Wet repellence results

The differences with and without the fountain solution indicate that samples 1 and 4 had the smallest difference, while samples 2 ( $A$ and $B$ side) and samples $5 B$ and $6 A$ do not posses noticeable difference regarding wet repellence. Sample 6B is interesting as almost no difference was observed between wetted and dry printed samples.

To evaluate the micro and macro porosity ratio to wet repellence we have compared the macro pores which are mainly influencing the water/dampening solution absorption with the optical density values measured on the test samples.

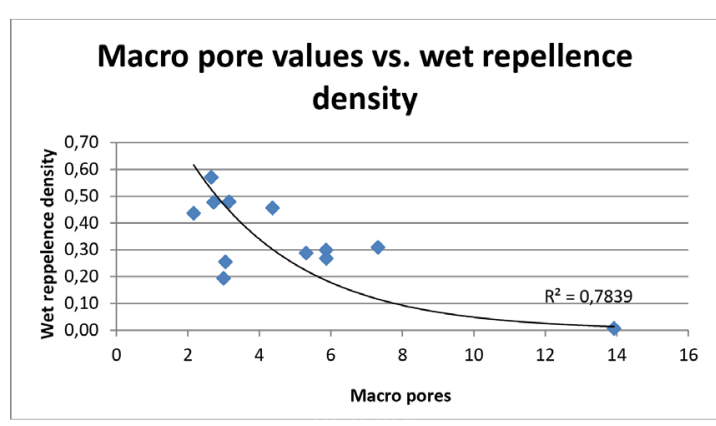

» Figure 6: The relationship between the macro pores values and the optical density of wet repellence 
From Figure 6. and with the calculation of the $\mathrm{R}^{2}$ factor $(0,78)$ of determination, we can see that with the number of macropores the wet repellence measured through optical density is decreasing and vice versa a small amount of macropores increases the wet repellence factor. The dampening solution does not have enough time due to small macroporosity to quickly absorb and this can cause wet repellence. Two samples were a bit of outlier but as the inner void porosity system is very complex and the micro and macro pore values are "dimensionless" the specific pore sizes and volumes are unknown. As the used testing ink has particles above $10 \mu \mathrm{m}$ and to $100 \mu \mathrm{m}$ which is a wide window for specific situations for example, if there is a printing speed variation of changes in the fountain solution application this could lead also to some differences between good and bad samples.

The liquid penetration curves measured with ultrasound showed also a good correlation with macropore number which indicates that water due to it high surface energy is mainly absorbed by larger pores which absorb more quickly as was noted by the Darcy Law.

\section{Conclusion}

On the basis of the concluded research we have tested six papers (some were reported as unsuitable for printing to the paper producer) using different test which could help the paper producer to change the calendaring settings (pressure, temperature) to gain optimal balance between micro and macro pores which define the absorption and setting properties of the paper substrates. Our results indicate that micropores do not influence the water repellency as considered to absorb oils like the vehicle from offset printing inks, while the calculated macropores and their ratio exponentially induce water repellence in offset printing. Values of macropores below the value of 5 tend to induce larger wet repellence values (with some exceptions) and good correlation was found between the speed of absorption and the optical density of prints. Also, samples which had low attenuation drop measured by the PDA absorption method (less than 10\% from the reference $100 \%$ signal ratio) within the first second. This method is very valuable as it is using inks similar that are used in the real process and can give a rough approximation of the porosity structure of the produced paper and help in troubleshooting. Exact pore sizes and properties can be more precisely gained by using more advanced technology like the $\mathrm{Hg}$ porosimetry or $\mathrm{x}$-ray tomography but which are currently not so easily accessible as the presented method. The outlying samples could also be tested with a dynamic contact angle to access more detailed information regarding paper surface properties.

\section{References}

Koivula, H., Bousfield, D. \& Toivakka, M. (2010) Improved Prediction of Offset Ink Setting Rates Based on Experimental Data and Filtration Equations. Industrial \& Engineering Chemistry Research, 49 (10), 4676-4681. Available from: doi: 10.1021/ie9014028

Lie, C. \& Kolseth, P. (2007) Aspects of water-induced mottle when printing on coated paper in sheet-fed lithographic offset. In: Enlund, N. and Lovreček, M. (eds.) 34th IARIGAI International Research Conference: Advances in Printing and Media Technology, 9-12 September, Grenoble, France. Zagreb, Acta Graphica Publishers. pp. 59-67.

Madstedt, S. (2008) The impact of coating composition on print mottle and print gloss variations in sheetded offset. Master thesis. Royal Institute of Technology, Stockholm.

Pal, L., Joyce, M. \& Fleming, P. (2006) Simple Method for Calculation of the Permeability Coefficient of Porous Media. TAPPI Journal. 5 (9), 10-16.

Preston, J., Elton, N., Legrix, A., Nutbeem, C. \& Husband, J. (2002) The role of pore density in the setting of offset printing ink on coated paper. TAPPI Journal. 1 (3), 3-5.

Resch, P., Bauer, W. \& Hirn, U. (2010) Pore Structure Change due to Calendering and its Effect on Ink Setting Behaviour - Review and Novel Findings. TAPPI Journal. 9 (1), 27-35.

Ridgway, C. \& Gane, P. (2005) Ink-Coating Adhesion: The Importance of Pore Size and Pigment Surface Chemistry. Journal of Dispersion Science and Technology. 25 (4), 469-480. Available from: doi: 10.1081/DIS-200025717

Ridgway, C., Schoelkopf, J. \& Gane, P. (2010) Competitive Absorption of Polar and Non-Polar Liquids into Latex Bound Porous Structures of Fine Ground Calcium Carbonate. Transport in Porous Media. 86 (3), 945964. Available from: doi: 10.1007/s11242-010-9666-9

Scheicher, L. (2009). Modificirana metoda mikro makro poroznosti. Grafičar. (3), 30-33.

Schoelkopf, J., Gane, P. \& Ridgeway, C. (2000) Influence of inertia on liquid absorption into paper coating structures. Nordic Pulp and Paper Research Journal. 15 (05), 422-430. Available from: doi: 10.3183/NPPRJ-2000-15-05-p422-430

Schoelkopf, J. (2002) Observation and modelling of fluid transport into porous paper coating structures. PhD Thesis, Unibersity of Plymouth, England

Wilson, L. (2000) What the printer should know about paper. 3rd ed. Pittsburgh, GATF press.

Xiang Y., Bousfield D., Hayes P. \& Kettle J. (2004) A model to predict ink-setting rates based on pore-size distributions. Journal of Pulp and Paper Science. 30 (5), 117-120. 


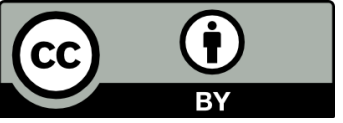

(C) 2018 Authors. Published by the University of Novi Sad, Faculty of Technical Sciences, Department of Graphic Engineering and Design. This article is an open access article distributed under the terms and conditions of the Creative Commons Attribution license 3.0 Serbia (http://creativecommons.org/licenses/by/3.0/rs/). 